\title{
The effect of flow turbulence on growth, nutrient uptake and stable carbon and nitrogen isotope signatures in Chara fibrosa
}

\author{
Champika Ellawala ${ }^{1,2 *}$, Takashi Asaeda ${ }^{2}$ and Kiyoshi Kawamura ${ }^{2}$ \\ ${ }^{1}$ Department of Civil and Environmental Engineering, Faculty of Engineering, University of Ruhuna, Hapugala, Galle, Sri Lanka \\ ${ }^{2}$ Institute for Environmental Science and Technology, Saitama University, 255 Shimo-okubo, Sakura, Saitama 338-8570, Japan
}

Received 24 January 2012; Accepted 1 May 2012

\begin{abstract}
Exposure to water movement has been observed to alter various processes in the plants including growth, hormone concentration and nutrient uptake. In the current study, Chara fibrosa was exposed to three different turbulence conditions and compared with a control. Turbulence was generated in the laboratory by using a vertically oscillating grid setup. Exposure to turbulence caused a reduction in shoot length and nutrient uptake in C. fibrosa. Variation of stable isotope composition was measured as a surrogate variable that is able to integrate variations of many physiological processes. It was initially hypothesized that the reduction of diffusion boundary layer around the plant will increase isotopic discrimination against ${ }^{13} \mathrm{C}$ and ${ }^{15} \mathrm{~N}$, when exposed to increasing turbulence. Although the results generally agree with the hypothesis, a trend of increment was observed in $\delta^{13} \mathrm{C}$ in the plants exposed to turbulent velocities from 0.46 to $1.93 \mathrm{~cm} \mathrm{~s}^{-1}$, against the hypothesis. Mechanical stress induced reduction of carbon uptake and lipid peroxidation due to the development of oxidative stress may be the reasons behind the above-mentioned trend. The study exhibits that the net effect of physical and physiochemical changes of the plants was displayed in $\delta^{13} \mathrm{C}$ signatures and it is important to consider physical conditions of the local environment, in using stable isotope signatures for ecosystem studies.
\end{abstract}

Key words: Turbulence / isotope / stress / carbon / nitrogen

\section{Introduction}

Aquatic plant growth, metabolism and distribution are observed to be influenced by water movement (Westlake, 1967; Madsen et al., 2001). In general, water movement on a small scale has positive effects on nutrient uptake and metabolism due to the reduction of thickness of diffusion boundary layer around leaves (Madsen et al., 1993; Nishihara and Ackerman, 2006). However, water movement does not necessarily enhance nutrient uptake; it can inhibit plant physiological processes becoming a stress to the plants. Reduction of growth, variations of growth hormone concentration and development of oxidative stress have been observed when plants are exposed to flow and/or turbulence (Ke and Li, 2006; Ellawala et al., 2011a, $2011 b$ ). In addition, reduction of the rate of photosynthesis, metabolism and reduction of nutrient uptake have also been observed in many aquatic plants, when they are exposed to water movement of any kind (Madsen et al., 1993; Ellawala et al., 2011a) and some authors hypothesized that this is a result of thigmomorphogenic effect

\footnotetext{
*Corresponding author: ellawala@eng.ruh.ac.1k
}

(Madsen and Sondergaard, 1983). Thigmomorphogenesis is known to alter growth hormone concentration and to develop oxidative stress in the plants (Chehab et al., 2009). It is impractical to measure each individual process on many plants. Rather, the impact of turbulence or similar processes on the plants could be understood by measuring surrogate variables which can integrate many physiological processes. One of the most widely used surrogate variables include the natural abundance of biologically important stable isotope pairs, denoted as $\delta^{13} \mathrm{C}$ and $\delta^{15} \mathrm{~N}$ (Robinson et al., 2000).

Plants have an isotopic discrimination against heavier isotopes in nature. Hence, the overall abundance of heavier isotope in the plant tissue is usually less than its carbon source, indicating that isotope discrimination occurs when incorporating carbon into the plant. Variations in the ${ }^{13} \mathrm{C} /{ }^{12} \mathrm{C}$ ratio may occur during the formation and destruction of bonds involving the carbon atom, or because of the other processes that are affected by mass, such as gaseous diffusion (Farquhar et al., 1989). Stable carbon and nitrogen isotope signatures have been increasingly used in ecology in exploring and understanding ecosystem relationships (Zeng et al., 2008). 
Table 1. Turbulence energy dissipation rate and measured turbulence velocity fluctuations ( $u$ ') at each depth for each tank. The standard deviation represents the spatial variation of turbulence velocity fluctuation in the horizontal plane.

\begin{tabular}{|c|c|c|c|c|c|c|}
\hline \multirow[b]{2}{*}{ Depth $(\mathrm{cm})$} & \multicolumn{3}{|c|}{ Turbulence energy dissipation rate $\left(\mathrm{m}^{2} \mathrm{~s}^{-3}\right)$} & \multicolumn{3}{|c|}{ Turbulence velocity fluctuations $\left(\mathrm{u}^{\prime}\right)\left(\mathrm{cm} \mathrm{s}^{-1}\right)$} \\
\hline & High & Medium & Low & High & Medium & Low \\
\hline$\overline{9.0}$ & $3.96 \times 10^{-5}$ & $4.96 \times 10^{-6}$ & $6.19 \times 10^{-7}$ & $2.43 \pm 0.61$ & $1.53 \pm 0.84$ & $0.63 \pm 0.39$ \\
\hline 12.0 & $1.06 \times 10^{-5}$ & $1.56 \times 10^{-6}$ & $1.96 \times 10^{-7}$ & $1.88 \pm 0.84$ & $0.91 \pm 0.44$ & $0.43 \pm 0.22$ \\
\hline 16.0 & $3.97 \times 10^{-6}$ & $4.96 \times 10^{-7}$ & $6.20 \times 10^{-8}$ & $1.48 \pm 0.67$ & $0.75 \pm 0.41$ & $0.33 \pm 0.14$ \\
\hline
\end{tabular}

However, the influence of abiotic factors on stable isotope signatures of the plants and algae were studied later (Finlay et al., 1999; Trudeau and Rasmussen, 2003). Field studies on aquatic plants have generally reported that $\delta^{13} \mathrm{C}$ values are to be enriched in ${ }^{13} \mathrm{C}$, in low-energy lentic systems than in high-energy lotic systems. In low-energy systems, the boundary layer around the plants is thick due to stagnant water. This results in lower nutrient diffusion rates, thus reducing the hormonal discrimination over a heavier isotope (Trudeau and Rasmussen, 2003). Although the variation of ${ }^{15} \mathrm{~N}$ is not explored much, there is a hypothesis that discrimination against ${ }^{15} \mathrm{~N}$ also further increased when exposed to higher current velocities (Trudeau and Rasmussen, 2003).

Charophytes - living form of characean algae - is found in both lentic and lotic ecosystems worldwide. Chara fibrosa C. Agardh ex A. Bruzelius - one species of charophytes was chosen for the current study. The growth, nutrient uptake and stable isotope compositions were measured in C. fibrosa. Chara is one of the members at the base of food webs, being a food source for many consumers. Hence, the variations of stable isotope composition in Chara due to the variations of environmental conditions they exposed, may affect isotope signatures of the consumers also. Therefore, the study aimed at observing the variation of stable isotope composition in C. fibrosa when exposed to different turbulence conditions, those encountered in natural ecosystems and to understand the underlying mechanisms governing those observations. The study was carried out in the laboratory by simulating three different turbulence conditions and one control.

\section{Materials and methods}

The experiment was conducted in 6-L microcosms $\left(15.7 \times 15.7 \times 24.5 \mathrm{~cm}^{3}\right)$ for a period of 12 weeks. The temperature was set at $23 \pm 2{ }^{\circ} \mathrm{C}$, and light was provided by fluorescence bulbs with a $12 \mathrm{~h}$ light/12 h dark photoperiod and light intensity ranging from 240 to $270 \mu \mathrm{mol} \mathrm{m} \mathrm{m}^{-2} \mathrm{~s}^{-1}$. The $\mathrm{pH}$ of the medium was in the range of $7.3 \pm 0.1$ (Gomes and Asaeda, 2009). The experimental setup consisted of four microcosms. Three microcosms were of different turbulence conditions; the other was the control, which lacked turbulence. All treatments were in triplicate.

\section{Generation of turbulence and its quantification}

Turbulence was generated in the laboratory using vertically oscillating horizontal grids that created three turbulence conditions without net flow. The grid oscillation frequencies were 1, 2 and $4 \mathrm{~Hz}$. The grid spacing (M) was set at $2.5 \mathrm{~cm}$, and the grid was made of $5 \mathrm{~mm}$ square Plexiglas rods. The stroke length (S) was $3 \mathrm{~cm}$, and the grids were oscillated from top of the tank, the mean grid position being $2 \mathrm{~cm}$ below the tank top. Turbulent velocity fluctuations were measured using a two-dimensional electromagnetic current meter (SF-5712, Tokyo-keisoku Corporation, Tokyo, Japan). The velocity of water was measured at nine different points, which were symmetrically distributed over the area. In addition, the velocity profile was measured at three depths $(9,12$ and $16 \mathrm{~cm}$ from the top of the tank) for each of the nine points. The measurements were taken at $10 \mathrm{~Hz}$ for $1 \mathrm{~min}$ at each point. Root mean velocity was separately calculated for each record and averaged to establish root mean velocity at a particular point. Average of the nine points was taken as the turbulence velocity ( $\left.u^{\prime}\right)$ at each depth in each tank. The average turbulent velocities in the tanks were $1.93 \pm 0.48$, $1.06 \pm 0.41$ and $0.46 \pm 0.15 \mathrm{~cm} \mathrm{~s}^{-1}$, respectively, in high, medium and low turbulent conditions (Table 1). The control had no turbulence. Since oscillating grids generate nearly isotropic and homogeneous turbulence, the vertical component should be the same as the measured horizontal component and was thus not measured (De Silva and Fernando, 1994). Turbulent energy dissipation rate $(\varepsilon)$ was calculated using empirical equations developed on grid generated turbulence (De Silva and Fernando, 1994; O'Brien et al., 2004) and depicted in Table 1.

$$
\varepsilon=\frac{1}{\beta}\left(\frac{2 C_{1}^{2}+C_{2}^{2}}{3}\right)^{3 / 2} \frac{M^{3 / 2} S^{9 / 2} f^{3}}{z^{4}}
$$

The values of the constants are $\beta=0.1$, $\mathrm{C}_{1}=0.18 \pm 0.04$ and $\mathrm{C}_{2}=0.22 \pm 0.05$ (De Silva and Fernando, 1994). Grid mesh size $M=2.5 \mathrm{~cm}$ and stroke length $S=3 \mathrm{~cm}$. $f$ is the grid oscillation frequency (1,2 and $4 \mathrm{~Hz}$ ) and $z$ is the distance from the mean position of the grid. Turbulence velocities generated in this study have been observed within plant canopies in streams and shallow lakes (Sanford, 1997; Sand-Jensen and Pedersen, 1999) and turbulence intensities were comparable with those occurring in shallow lakes (Sanford, 1997; Wuest and Lorke, 2003).

\section{Plant material and growth conditions}

C. fibrosa was cultured for approximately over 3 months in the laboratory at a temperature of $23 \pm 2{ }^{\circ} \mathrm{C}$. 
Twelve apical tips of 4-5 cm in length and having 2-3 internodes were harvested and planted in each tank, each positioned with about $2-2.5$ internodes $(3-4 \mathrm{~cm})$ above the substrate. The substrate was a $4-\mathrm{cm}$ thick peaty soil that was collected locally and sieved (1 mm mesh) to remove debris. The sediment added micronutrients to the growth media and supported plant anchorage. Water column nutrients were maintained at concentrations of $0.3 \mathrm{mg} \mathrm{L}^{-1}$ nitrate and $0.1 \mathrm{mg} \mathrm{L}^{-1}$ phosphate and $10.0 \mathrm{mg} \mathrm{L}^{-1}$ dissolved inorganic carbon (DIC) by using $\mathrm{NaNO}_{3}$, $\mathrm{K}_{2} \mathrm{HPO}_{4}$ and $\mathrm{NaHCO}_{3}$ (Wako Chemicals, Tokyo, Japan), respectively, for adjustments (Gomes and Asaeda, 2009). DIC, nitrate and phosphate concentrations in water were measured weekly and adjusted accordingly. DIC was measured using a total organic carbon analyser (TOC 5000 A, Shimadzu Co. Ltd, Tokyo, Japan). Total ammonia concentration in the water was determined by the phenate method (APHA, 1998) but was not detectable. Phosphate and nitrate concentration were also determined according to the standard methods (APHA, 1998). Nitrate concentration was measured by using a spectrophotometer (Shimadzu UV mini 1410, Shimadzu Co. Ltd, Tokyo, Japan) for absorbance at $220 \mathrm{~nm}$ and correction for DOC at $275 \mathrm{~nm}$ after addition of $0.2 \mathrm{ml}$ of $1 \mathrm{~N} \mathrm{HCl}$ to the sample. Phosphate concentration was determined by using the molybdate method for measuring the absorbance at $830 \mathrm{~nm}$ (APHA, 1998).

\section{Growth measurements and chemical analysis}

The shoot length was measured at the end of the experiment period and calculated by summing up the length of all the branches. Fresh plant samples were extracted in $100 \mathrm{mM}$ phosphate buffer (Zhang et al., 2009) and the supernatant was used for the APX activity and CAT activity assays (Parida and Jha, 2010). The results are presented in $\mu$ mol $\mathrm{H}_{2} \mathrm{O}_{2}$ destroyed per minute per $\mathrm{g}$ of fresh weight $\left(\mu \mathrm{mol} \mathrm{H}_{2} \mathrm{O}_{2} \mathrm{~min}^{-1} \mathrm{~g} \mathrm{FW}^{-1}\right)$. Plant samples were dried at $70{ }^{\circ} \mathrm{C}$ for $48 \mathrm{~h}$ and dried samples were used for analysing isotope composition, total carbon (TC) content and total nitrogen (TN) content of the tissues. Each sample was crushed and placed in a tin capsule (between 1.5 and $2.0 \mathrm{mg}$ of sample per capsule) for analysis by mass spectrometry in a isotope-ratio mass spectrometer (IsoPrime 100, Isoprime house, Cheadle, UK) coupled with an elemental analyser on line (vario MICRO, Elementar Analysensysteme Gmbh, Hanau, Germany). The results of isotopic analysis are presented in conventional delta $(\delta)$ notation, defined as $\delta X=\left[\left(R_{\text {sample }}-R_{\text {standard }}\right)-1\right] \times 1000$, where $X$ is ${ }^{13} \mathrm{C}$ or ${ }^{15} \mathrm{~N}$ and $R$ is the ratio of ${ }^{13} \mathrm{C} /{ }^{12} \mathrm{C}$ or ${ }^{15} \mathrm{~N} /{ }^{14} \mathrm{~N}$. Plant TC and $\mathrm{TN}$ contents were determined in a $\mathrm{CHN}$ Corder-Auto sampler (MT-5, Yanaco Co. Ltd, Kyoto, Japan) by using $3.0 \pm 0.1 \mathrm{mg}$ of dried plant sample and the results are presented as percentage $(\%)$.

\section{Statistical analysis}

All the data are presented as means \pm SD. The homogeneity of variance test was carried out on datasets before carrying out ANOVA. For comparison of differences among each group, one-way ANOVA was performed with post-hoc Tukey's test. Statistical analysis was performed by using SPSS software package (Release 16, SPSS Inc., Chicago, IL, USA).

\section{Results}

\section{Final shoot length}

The average shoot length of the plants exposed to high, medium and low turbulence and the control was $6.40 \pm 1.51,12.00 \pm 1.55,15.53 \pm 3.55$ and $17.10 \pm 2.97$ $\mathrm{cm}$, at the end of the experiment period. The average shoot length was significantly less in the plants exposed to high and medium turbulence compared with the plants exposed to low turbulence and the control (ANOVA, $\left.F_{(3,8)}=16.505, P<0.001\right)$.

\section{CAT and APX activity}

CAT activity was $1.39 \pm 0.66,2.36 \pm 0.78,0.82 \pm 0.03$ and $0.80 \pm 0.00 \mu \mathrm{mol} \mathrm{H} \mathrm{H}_{2} \mathrm{~min}^{-1} \mathrm{~g} \mathrm{FW}^{-1}$ and APX activity was $8.39 \pm 1.09,6.22 \pm 1.52,4.51 \pm 0.62$ and $2.05 \pm 0.48 \mu \mathrm{mol} \mathrm{H}_{2} \mathrm{O}_{2} \min ^{-1} \mathrm{~g} \mathrm{FW}^{-1}$, respectively, in the plants exposed to high, medium and low turbulence and the control, at the end of the experiment period. Plants exposed to high and medium turbulence had significantly high CAT (ANOVA, $F_{(3,8)}=161.200, P<0.001$ ) and APX (ANOVA, $F_{(3,8)}=20.877, P<0.001$ ) activities compared with the plants exposed to low turbulence and the control.

\section{Carbon and nitrogen isotope composition}

Figure 1 shows $\delta^{13} \mathrm{C}$ and $\delta^{15} \mathrm{~N}$ values of the plants exposed to different turbulence conditions and the control. $\delta^{13} \mathrm{C}$ in the plants exposed to low turbulence was significantly less than both the plants exposed to high turbulence and the control (ANOVA, $F_{(3,8)}=65.549$, $P<0.006)$. The control had the lowest discrimination over ${ }^{13} \mathrm{C} . \delta^{15} \mathrm{~N}$ of the plants exposed to high and medium turbulence was significantly less than the plants exposed to low turbulence and the control (ANOVA, $F_{(3,8)}=383.152$, $P<0.001)$; however, there was no trend of elevation of ${ }^{15} \mathrm{~N}$ in the plants exposed to high and medium turbulence as observed in ${ }^{13} \mathrm{C}$.

\section{TC and TN contents in plant tissues}

TC and TN contents of the plant tissues are shown in Figure 2. TC and TN contents of the plants exposed to high and medium turbulence were significantly less than the plants exposed to low turbulence and the control (ANOVA, $F_{(3,8)}=205.5, P<0.001$ for TC and $F_{(3,8)}=109.659, P<0.001$ for TN). 
(a)

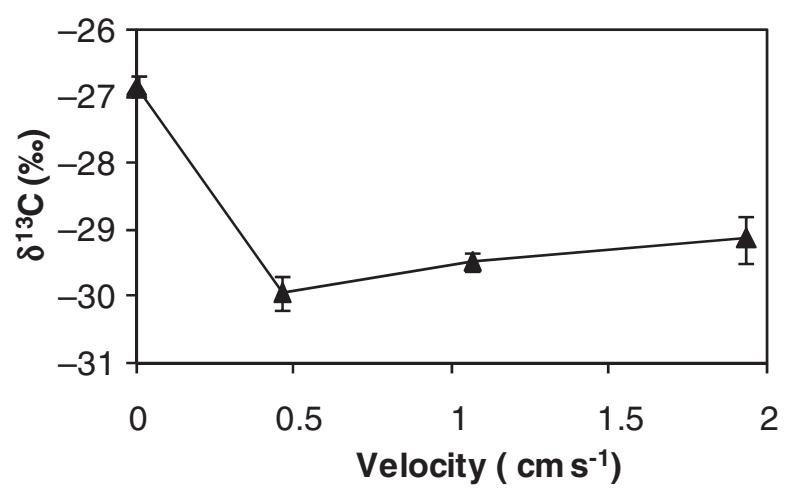

(b)

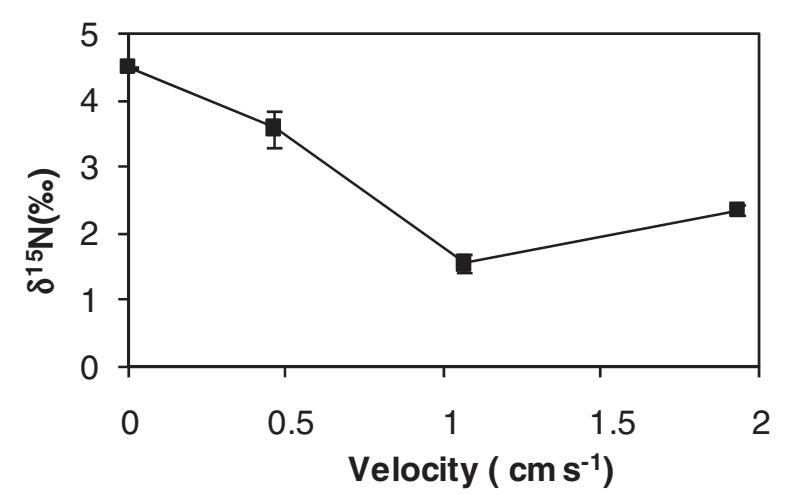

Fig. 1. Variation of (a) $\delta^{13} \mathrm{C}$ and (b) $\delta^{15} \mathrm{~N}$ in Chara fibrosa exposed to different turbulence conditions and the control at the end of the experiment period.

\section{Discussion}

Exposure to turbulence caused significant reduction in shoot length of $C$. fibrosa. Shoot length of the plants exposed to high turbulence was 2.7 times shorter than the plants grown in the control, at the end of the experiment period. This variation agrees well with the previous observation of the plants exposed to water movement; for instance, Chara delicatula exposed to frequent wave action was observed to be 4.7 times shorter than the plants grown in a sheltered area (Szmeja and Galka, 2008). Mechanical stress generated by water movement has been observed to reduce growth hormone concentrations and to retard growth due to accumulation of reactive oxygen molecules (Ellawala et al., 2011b). TC and TN contents of the plants exposed to high and medium turbulence have been significantly less than TC and TN contents of the control plants, supporting the hypothesis that nutrient uptake is reduced when exposed to mechanical stress generated by water movement (Madsen and Sondergaard, 1983; Madsen et al., 1993).

Numerous studies in the field and laboratory have confirmed that $\delta^{13} \mathrm{C}$ values enriched in ${ }^{13} \mathrm{C}$, in low-energy lentic systems than in high-energy lotic systems (Finlay et al., 1999; Trudeau and Rasmussen, 2003). In highenergy lotic systems, the discrimination is increased due to (a)

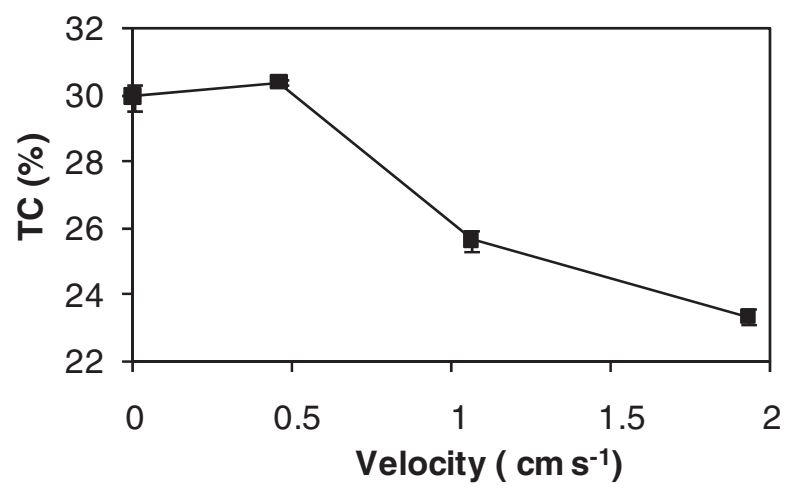

(b)

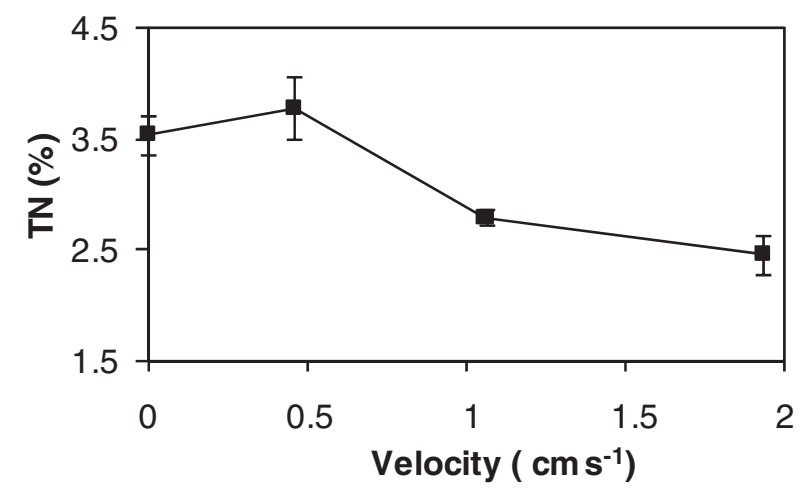

Fig. 2. Variation of (a) TC and (b) TN content in Chara fibrosa exposed to different turbulence conditions and the control at the end of the experiment period.

easy uptake of nutrients, through reduced diffusion boundary layer around the plants (Trudeau and Rasmussen, 2003). Even though, there is less information on nitrogen isotopic fractionation, same boundary layer/ diffusion hypothesis is observed to be valid for $\delta^{15} \mathrm{~N}$ values (Trudeau and Rasmussen, 2003). The current study also supports the above-mentioned boundary layer/diffusion hypothesis in general, acquiring less $\delta^{13} \mathrm{C}$ and $\delta^{15} \mathrm{~N}$ values in the exposure to the turbulence compared with the control. However, it shows a trend of increment in $\delta^{13} \mathrm{C}$ in the plants exposed to turbulent velocities in the range from 0.46 to $1.93 \mathrm{~cm} \mathrm{~s}^{-1}$. Oxidative stress has been developed in the plants exposed to high and medium turbulence compared with low turbulence and the control, as observed by increased CAT and APX activities (Ellawala et al., 2011a). It is well known that the development of oxidative stress and accumulation of active oxygen molecules are responsible for lipid oxidation. Lipids are fairly less in ${ }^{13} \mathrm{C}$; hence, lipid peroxidation may cause $\delta^{13} \mathrm{C}$ values to be enriched in ${ }^{13} \mathrm{C}$, in the plant material (Jardine et al., 2009). The plants exposed to high and medium turbulence were enriched in ${ }^{13} \mathrm{C}$ compared with the plants exposed to low turbulence, supporting the above hypothesis. Further, variation of $\delta^{15} \mathrm{~N}$ did not show any significant elevation in ${ }^{15} \mathrm{~N}$ in the plants exposed to high and medium turbulence compared with the plants exposed to low turbulence. Therefore, it can be hypothesized that 
the net effect of reduction of thickness of diffusion boundary layer and lipid peroxidation is observable in $\delta^{13} \mathrm{C}$ values. In addition, photosynthetic carbon uptake has been observed to reduce when the plants are exposed to current velocity induced movements (Madsen and Sondergaard, 1983; Madsen et al., 1993). There is an opinion that mechanical stress generated in the plants, due to the movement of water causes this observation (Madsen and Sondergaard, 1983). Hence, reduced carbon uptake to the plant may reduce the discrimination over a heavier isotope. One or both mechanisms discussed above may be responsible for ${ }^{13} \mathrm{C}$ enrichment in the plants exposed to high and medium turbulence compared with the plants exposed to low turbulence, against the boundary layer/ diffusion hypothesis.

Stable isotope signatures have been widely used in ecosystem studies due to their ability to reflect trophic dynamics and their importance as source indicators to provide spatial information about the physical and biological processes (Rasmussen and Trudeau, 2007). Physical mechanisms such as reduction of thickness of diffusion boundary layer (Trudeau and Rasmussen, 2003; Rasmussen and Trudeau, 2007) and different abiotic stresses such as exposure to allopathic substances (Hussain and Reigosa, 2011), drought and salinity (Amor and Cuadra-Crespo, 2011; Li et al., 2011) also have been observed to influence stable isotope signatures due to the alterations of different physiochemical mechanisms of the plants. In this study, variations of $\delta^{13} \mathrm{C}$ and $\delta^{15} \mathrm{~N}$ of the plants support the hypothesis that $\delta^{13} \mathrm{C}$ and $\delta^{15} \mathrm{~N}$ signatures of the plants may exhibit the net result of the effect of physical and physiochemical variations. Therefore, this study highlights that, it is important to consider the physical conditions of the local environment in using stable isotope signatures for ecosystem studies.

Acknowledgements. This research was financially supported by a Research Grant-in-Aid from the Ministry of Education, Culture, Sports, Science and Technology of Japan.

\section{References}

Amor F.M.D. and Cuadra-Crespo P., 2011. Alleviation of salinity stress in broccoli using foliar urea or methyljasmonate: analysis of growth, gas exchange and isotope composition. Plant Growth Regul., 63, 55-62.

APHA (Ed.) 1998. Standard Methods for the Examination of Water and Wastewater. APHA, AWWA, and WEF, Washington.

Chehab W., Eich E. and Braam J., 2009. Thigmomorphogenesis: a complex plant response to mechano-stimulation. J. Exp. Bot., 60, 43-56.

De Silva I.P.D. and Fernando H.J.S., 1994. Oscillating grids as a source of nearly isotropic turbulence. Phys. Fluids, 6, 24552464.

Ellawala C., Asaeda T. and Kawamura K., 2011a. Influence of flow turbulence on Chara fibrosa: growth, stress, and tissue carbon content. J. Freshwater Ecol., 26, 507-515.
Ellawala K.C., Asaeda T. and Kawamura K., 2011b. The effect of flow turbulence on plant growth and several growth regulators in Egeria densa Planchon. Flora, 206, 1085-1091.

Farquhar G.D., Ehleringer R. and Hubic K.T., 1989. Carbon isotope discrimination and photosynthesis. Annu. Rev. Plant Physiol. Plant Mol. Biol., 40, 503-537.

Finlay J.C., Power M.E. and Cabana G., 1999. Effects of water velocity on algal carbon isotope ratios: implications for river food web studies. Limnol. Ocean., 44, 1198-1203.

Gomes P.I.A. and Asaeda T., 2009. Phycoremediation of chromium (vi) by Nitella and impact of calcium encrustation. J. Hazard. Mater., 166, 1332-1338.

Hussain M.I. and Reigosa M.J., 2011. A chlorophyll fluorescence analysis of photosynthetic efficiency, quantum yield and photon energy dissipation in psii antennae of Lactuca sativa L. Leaves exposed to cinnamic acid. Plant Physiol. Biochem., 49, 1290-1298.

Jardine K., Karl T., Lerdau M., Harley P., Guenther A. and Mak J.E., 2009. Carbon isotope analysis of acetaldehyde emitted from leaves following mechanical stress and anoxia. Plant Biol., 11, 591-597.

Ke X. and Li W., 2006. Hormonal correlates of seedling growth of two Vallisneria species grown at different current velocities. Hydrobiologia, 556, 243-249.

Li Y., Zhao H., Duan B., Korpelainen H. and Li C., 2011. Effect of drought and ABA on growth, photosynthesis and antioxidant system of Cotinus coggygria seedlings under two different light conditions. Environ. Exp. Bot., 71, 107-113.

Madsen J.D., Chambers P.A., James W.F., Koch E.W. and Westlake D.F., 2001. The interaction between water movement, sediment dynamics and submersed macrophytes. Hydrobiologia, 444, 71-84.

Madsen T. and Sondergaard M., 1983. The effects of current velocity on the photosynthesis of Callitriche stagnalis scop. Aquat. Bot., 15, 187-193.

Madsen T.V., Enevoldsen H.O. and Jørgensen T.B., 1993. Effects of water velocity on photosynthesis and dark respiration in submerged stream macrophytes. Plant Cell Environ., 16, 317-322.

Nishihara G.N. and Ackerman J.D., 2006. The effect of hydrodynamics on the mass transfer of dissolved inorganic carbon to the freshwater macrophyte Vallisneria americana. Limnol. Ocean., 51, 2734-2745.

O’Brien K., Meyer D., Waite A., Ivey G. and Hamilton D., 2004. Disaggregation of Microcystis aeruginosa colonies under turbulent mixing: laboratory experiments in a grid-stirred tank. Hydrobiologia, 519, 143-152.

Parida A.K. and Jha B., 2010. Antioxidative defense potential to salinity in the euhalophyte Salicornia brachiata. J. Plant Growth Regul., 29, 137-148.

Rasmussen J.B. and Trudeau V., 2007. Influence of velocity and chlorophyll standing stock on periphyton $\delta^{13} \mathrm{C}$ and $\delta^{15} \mathrm{~N}$ in the ste. Marguerite river system, Quebec. Can. J. Fish. Aquat. Sci., 64, 1370-1381.

Robinson D., Handley L.L., Scrimgeour G.M., Gordon D.C., Forster D.B. and Ellis R.P., 2000. Using stable isotope natural abundences $\left(\delta^{15} \mathrm{~N}\right.$ and $\left.\delta^{13} \mathrm{C}\right)$ to integrate stress responses of wild barley (Hordeum spontaneum C. Koch.) genotypes. J. Exp. Bot., 55, 41-50.

Sand-Jensen K. and Pedersen O., 1999. Velocity gradients and turbulence around macrophyte stands in streams. Freshwater Biol., 42, 315-328. 
Sanford L.P., 1997. Turbulent mixing in experimental ecosystem studies. Marine Ecol. Prog. Series, 161, 265-293.

Szmeja J. and Galka A., 2008. Phenotypic responses to water flow and wave exposure in aquatic plants. Acta Soc. Bot. Pol., 77, 59-65.

Trudeau V.R. and Rasmussen J.B., 2003. The effect of water velocity on stable carbon and nitrogen isotope signatures of periphyton. Limonol. Ocean., 48, 2194-2199.

Westlake D.F., 1967. Some effects of low velocity currents on the metabolism of aquatic macrophytes. J. Exp. Bot., 18, 187207.
Wuest A. and Lorke A., 2003. Small scale hydrodynamics in lakes. Ann. Rev. Fluid Mech., 35, 373-412.

Zeng Q.F., Kong F.X., Zhang E.L., Tan X. and Wu X.D., 2008. Seasonality of stable carbon and nitrogen isotopes within the pelagic food web of Taihu lake. Ann. Limnol. - Int. J. Lim., 44, 1-6.

Zhang H., Ye Y.K., Wang S.H., Luo J.P., Tang J. and Ma D.F., 2009. Hydrogen sulfide counteracts chlorophyll loss in sweet potato seedling leaves and alleviates oxidative damage against osmotic stress. Plant Growth Regul., 58, 243-250. 